\title{
LA LITERATURA DE VALPARAÍSO: ENTRE LA DESTERRITORIALIZACIÓN Y EL EXTRAÑAMIENTO
}

Valparaíso's literature: between deterritorialization and alienation

\author{
Ximena Figuera Flores* \\ Felipe González Alfonso **
}

Resumen

Valparaíso es un ejemplo paradigmático de las crisis e inestabilidades del capitalismo y de la modernización latinoamericana durante los siglos XIX y XX. Su historia de riqueza, segregación, cosmopolitismo y decadencia, se proyecta en la escritura respecto de la ciudad, que problematizamos a partir de los conceptos de desterritorialización y extrañamiento, ya que percibimos una presencia importante de autores extranjeros y afuerinos en la producción literaria porteña. Para analizar la elaboración textual de unas subjetividades cuyos referentes y marcos culturales se tensionan en Valparaíso, proponemos siete períodos: 1) de los viajeros ilustrados; 2) de los debates fundacionales; 3) del modernismo y la poesía social; 4) de las vanguardias expresionista e imaginista; 5) de la novela social; 6) de la novela del aprovinciamiento; 7) y de la poesía del exilio, en que el proceso se invierte y algunos poetas porteños escriben acerca de Valparaíso en el extranjero.

Palabras clave: Valparaíso, literatura, desterritorialización, extrañamiento.

Abstract

Valparaíso is a paradigmatic example of Capitalism's crisis and instabilities and of Latin American modernization during the XIX and XX centuries. Its history of wealth, segregation, cosmopolitism, and decadence is projected in the writings about the city, which we problematize based on the concepts of deterritorialization and alienation, since we perceive a significant presence of foreign and outsider authors in the literary production of Valparaíso. To analyze the textual elaboration of some subjectivities whose points of reference and cultural frameworks are tensioned in Valparaíso, we propose seven periods: 1) the enlightenment travellers; 2) the foundational debates; 3) modernism and social poetry; 4) the expressionist and imaginist vanguards; 5) the social novel; 6) the provincial novel; 7) and the poetry of exile, where the process reverses and some local poets write about Valparaíso while overseas.

Key words: Valparaíso, literature, deterritorialization, alienation.

\section{DESTERRITORIALIZACIÓN Y EXTRAÑAMIENTO}

El concepto de territorio abarca mucho más que su dimensión física; se trata de un conjunto de significados que configura a los sujetos y sus relaciones y, en consecuencia, las formas en que estos habitan y comprenden el mundo. Es este sentido amplio el que Deleuze y Guattari, según María Teresa Herner, que estudia las conexiones entre la desterritorialización y la geografía, tienen en cuenta cuando 
extienden el término más allá de sus utilizaciones por parte de la etología y la etnología, al decir que el territorio "es un conjunto de representaciones las cuales van a desembocar, pragmáticamente, en una serie de comportamientos, inversiones, en tiempos y espacios sociales, culturales, estéticos, cognitivos" (citado por Herner, 2009, p. 166). Además, en la medida en que, entendido de esta manera, el territorio pertenece al orden simbólico, es susceptible, entonces, de sobrepasar sus límites jurisdiccionales, de atravesar fronteras nacionales y entrar en diálogo con otros imaginarios territoriales. A este respecto, en un artículo de enfoque similar al de Herner, que conecta la desterritorialización con las problemáticas migratorias, la frontera y la identidad, Miriam Reyes Tovar piensa justamente que:

[...] las fronteras nacionales no solo son atravesadas físicamente, sino que también se hacen de forma perceptual, imaginaria, emotiva, ya que [...] en la migración los sujetos inmersos en este proceso, llevan consigo un movimiento de símbolos e información con respecto al lugar del cual parten, es decir, su espacio vivido (2011, p. 6).

Tal "movimiento", que implica la pérdida del territorio concreto, supone, sin embargo, la posibilidad de una reterritorialización o nuevo agenciamiento territorial, en que los imaginarios propios del lugar de origen, con su carga emocional y simbólica, son resignificados al enfrentarse a los imaginarios del nuevo territorio. En este sentido, el proceso desterritorialización/reterritorialización, piensa Reyes, desde su punto de vista geográfico, flexibiliza el campo de acción de los contenidos subjetivos en el mismo momento en que estos se transforman, proceso que cuestiona el sentido tradicional del territorio en tanto cerco geopolítico (2011, p. 9).

Con todo, creemos que no debe soslayarse el hecho de que este enfrentamiento y síntesis de imaginarios es, primeramente, una situación de pérdida y desarraigo y, por tanto, una situación esencialmente dolorosa, donde predomina la experiencia del extrañamiento. Este afecto que, para el investigador brasileño Gustavo Lins Ribeiro, es propio del antropólogo, también es extensible, pensamos, al escritor exiliado, que se instala en una comunidad cuyos códigos sociales le son desconocidos, y a la que, quiéralo o no, debe enfrentar, pensar e incorporar a su escritura:

Al no participar como nativo en las prácticas sociales de las poblaciones que estudia, en las imposiciones cognitivas de una determinada realidad social [...] experimenta, existencialmente, el extrañamiento como una unidad contradictoria: al ser, al mismo tiempo, aproximación y distanciamiento (1989, p. 66).

Aproximación y distanciamiento son las dos acciones que estructuran el extrañamiento, pues, cuando este se me da como experiencia, por un lado, percibo o siento algo cerca que es extraño, ajeno, distante, o bien extraño (añoro) algo que está lejos y, sin embargo, siento cercano y familiar. Pero ambos movimientos también hacen posible la desterritorialización: es la distancia la que me desterritorializa y me obliga a reterritorializarme, a elaborar una nueva forma de acercamiento a lo que me era 
familiar, integrando en ello lo extraño. Esta tensión de fuerzas contrarias y complementarias nos permite detectar algunos elementos comunes de la literatura de Valparaíso, al menos en los que consideramos sus momentos más importantes.

\section{AUGE Y CAÍDA DE VALPARAÍSO}

Si se observa la literatura de Valparaíso a la luz de las reflexiones anteriores, se descubre que una parte no menor de ella la escriben autores extranjeros y afuerinos (chilenos de otras regiones); sujetos desterritorializados, arrojados al extrañamiento por diversas circunstancias propias de los procesos modernizadores latinoamericanos, que en Valparaíso se inician en las primeras décadas del siglo XIX. Más precisamente, es en 1820 cuando se registran las primeras disposiciones legales para renovar la infraestructura del puerto con el fin de regular, organizar y facilitar la pujante actividad naviera, comercial y financiera: bodegas, almacenes públicos y privados y depósitos flotantes, le permiten a Valparaíso convertirse en un puerto de importancia continental (Ortega, 1987, p. 103). A esto se suma la presencia de inmigrantes europeos que reproducen en Valparaíso su estilo de vida y sus costumbres, lo que, a su vez, replican las clases acomodadas de la ciudad (Ortega, 1987, p. 107), preocupadas ahora por el bienestar y el diseño de sus viviendas: entre otros refinamientos, empapelan las paredes y cubren el suelo con pisos de madera y alfombras. Pero esto se produce "en agudo contraste con el exterior" (Ortega, 1987, p. 108). En efecto, simultáneamente comienza un proceso de sectorización del espacio urbano que segrega a las clases bajas: el puerto se erige como el centro fuerte de la actividad comercial, mientras que el Almendral mantiene su aspecto rural y residencial que ha heredado de la Colonia, en tanto que "[e]n los cerros y quebradas comenzó a agruparse la gente pobre, aquellos cuyos ranchos eran desplazados en la parte plana por las nuevas construcciones, y algunos ingleses que dieron inicio al poblamiento del Mount Pleasant o Cerro Alegre" (Ortega, 1987, p. 108). ${ }^{1}$.

No obstante, en la década de los cincuenta del siglo XIX Valparaíso ingresa a su "época dorada" (Ortega, 1987, p. 109) que se incrementa poco después, en 1861, momento en el que "Valparaíso entró en una etapa sin precedentes de prosperidad y crecimiento que bien podría ser calificada como una suerte de época de oro, dentro de una época dorada; esta se habría de prolongar hasta, aproximadamente, 1875" (Ortega, 1987, p. 111). Gracias a la considerable acumulación de riqueza producto de la

\footnotetext{
${ }^{1}$ Aun con su tono aristocratizante, que desprecia a pobres y resiente de burgueses, nadie como Joaquín Edwards Bello ha descrito este proceso de segregación social (y racial) que hoy llamaríamos de gentrificación. Refiriéndose al Valparaíso de 1865, anota en 1934: "Esa población de los cerros hace un contraste con la del plan o parte baja, exceptuando un cerro central [el Cerro Alegre]. Arriba está la plebe; abajo, las autoridades, los comerciantes, la alta sociedad. Generalmente son extranjeros los que empujan al cerro a los antiguos y auténticos habitantes de la caleta, que en la Conquista se llamó Quintil. La ola europea, triunfadora, va repeliendo hasta las quebradas pobres a los residuos o sobrevivientes de changos, mulatos y mestizos. El plan es la ley de Darwin. Hacia arriba va la ola derrotada comiendo pescado seco y cebolla" (Edwards Bello, 2001, p. 271).
} 
actividad financiera ligada a la minería del norte, la ciudad se convierte en punto de importancia central para el circuito mercantil capitalista que gracias a la industrialización y los nuevos medios de transporte genera un intercambio de mercancías a nivel mundial. Valparaíso es, entonces, el primer puerto del Pacífico donde recalan obligatoriamente los barcos que vienen desde Europa con mercancías y viajeros, los que le otorgan a la ciudad una atmósfera ostentosa y cosmopolita.

Este ciclo de auge concluye lenta e irrevocablemente debido a varias circunstancias, como la disminución del mercado internacional; la pérdida del manejo financiero de Valparaíso en las minas salitreras y el consiguiente desplazamiento del eje económico nacional hacia el norte; la renovación de la infraestructura comunicacional ferroviaria a comienzos del siglo XX entre San Francisco y Nueva York y por el istmo de Panamá y, por supuesto, la construcción del Canal de Panamá en 1914 (Estrada Turra, 2013, p. 166-167), que le arrebató a Valparaíso sus privilegios como "el primer polo de desarrollo comercial del país", debido a "su posición estratégica en la ruta AtlánticoPacífico" (Sánchez y Jiménez, 2011, p. 569). Luego, la llamada crisis de 1929 le da, por así decir, el tiro de gracia a Valparaíso: produjo una baja en el tráfico de importaciones y exportaciones que dañó definitivamente la actividad portuaria, industrial y comercial de la ciudad (Bravo, 1987, p. 179).

\section{SIETE MOMENTOS}

El auge y la estrepitosa caída de Valparaíso, el hecho de ser la ciudad un ejemplo paradigmático de las crisis e inestabilidades del capitalismo y la modernización latinoamericana; su historia de riqueza, segregación, cosmopolitismo y decadencia, potencia, sin embargo, la formación de un campo literario e influye en la forma en que la ciudad es representada. Esto se percibe ejemplarmente en los que consideramos los siete momentos más importantes de la literatura porteña desde sus orígenes en el siglo XIX y teniendo como límite las dos décadas de la dictadura militar: 1) durante la primera mitad del siglo XIX, en el período de los viajeros ilustrados, con el Diario de María Graham (1785-1842); 2) un par de décadas después, en el marco de los debates que fundan la literatura nacional entre Andrés Bello (1781-1865), Domingo Faustino Sarmiento (1811-1888) y José Victorino Lastarria (1817-1888); 3) en las últimas dos décadas del siglo XIX, cuando llegan a la ciudad los poetas Rubén Darío (1867-1916) y Carlos Pezoa Véliz (1879-1908); 4) en los años veinte y treinta del siguiente siglo, con la irrupción del expresionismo de Zsigmond Remenyik (1900-1962) y el imaginismo de Salvador Reyes (1899-1970); 5) en los años cincuenta, con las novela social de Manuel Rojas (1896-1973) y Armando Méndez Carrasco (1915-1984); 6) en la siguiente década y hasta principio de los setenta, con las novelas del aprovinciamiento de Carlos León y Juan Uribe Echevarría (1908-1988); 7) y en las dos décadas de la dictadura militar, con la poesía del exilio, en que el proceso se invierte y algunos poetas oriundos de Valparaíso, como Alicia Galaz (1936-2003), Eduardo Embry (1938), Luis Mizón (1942) y Osvaldo "Gitano" Rodríguez (1943-1996), escriben la literatura de la ciudad 
en el extranjero ${ }^{2}$. Bajo un enfoque que cruza la desterritorialización y el extrañamiento, vemos en los siete hitos mencionados -que, además, evidencian la predominancia de ciertos géneros literarios en distintos momentos- la elaboración textual de unas subjetividades cuyos referentes y marcos culturales de orientación se tensionan en el intento de dar cuenta de una realidad que les es desconocida.

\section{LOS VIAJEROS ILUSTRADOS}

Un primer momento de las letras porteñas lo constituyen los diarios y memorias de viajeros europeos atraídos por el auge de las primeras décadas del siglo XIX, y cuyo afán científico y cultural, de cuño ilustrado, orienta aspiraciones de ascenso social. El investigador de la cultura porteña popular, Marco Chandía, revalora estas narrativas mediante dos vías interpretativas. Por un lado, dice, Valparaíso se describe en ellas mediante un cúmulo de prejuicios europeizantes que señalan dónde se encuentra la barbarie (casi siempre en el particular modus vivendi de sus habitantes) y dónde los potenciales civilizadores (por lo general en las materias primas susceptibles de ser explotadas). Queda así al descubierto que "el afán que moverá a estos nuevos visitantes [...] no es otro que el de expandir el capital a escala mundial" (Chandía, 2013, p. 139). Pero, por otro lado, añade Chandía, la tendencia descriptiva y costumbrista en los textos de estos visitantes, los abre a la representación y el reconocimiento de "un mundo otro", a contrapelo del discurso imperialista: "...por debajo de este reprochable prejuicio eurocéntrico, se nos brinda el primer bosquejo de una sociedad marcadamente heterogénea que habita el Puerto, imagen representativa de la primera transculturación latinoamericana" (2013, p. 139).

Dentro del grupo de estos viajeros decimonónicos extendidos por todo el continente, Mary Louise Pratt, autora en cuyas reflexiones sustenta Chandía su investigación, señala, además, dos tendencias, en una evidente división del trabajo según criterios de género: por un lado, están los ansiosos capitalistas ingleses ávidos de ganancias bajo el amparo del progreso y, por otro, las "exploradoras sociales", mujeres extranjeras que, de modo complementario, se ocupan de indagar y registrar la vida social y política de su nuevo entorno (Chandía, 2013, p. 141). En el contexto porteño, los primeros produjeron una abundante y fragmentaria literatura repartida en cartas y anotaciones; en el segundo grupo destaca el Diario de mi residencia en Chile en 1922 de la inglesa María Graham, publicado en 1824. La lectura de Chandía nos permite vislumbrar el proceso de desterritorialización/reterritorialización sufrido por estos viajeros: el tópico civilización/barbarie, marco de comprensión europeo, se tensiona, se "extraña" en las exploradoras sociales, lo que da paso a un minucioso costumbrismo, donde lo que antes era simplemente incivilizado se despolariza o relativiza al observarse en su contexto.

\footnotetext{
${ }^{2}$ Este período podría extenderse hasta la actualidad -empalmándose con los momentos siguientes: la literatura de los 90 y 2000 - si consideramos a quienes como Luis Mizón y Eduardo Embry continúan hasta hoy su labor creativa en el extranjero.
} 
Por ejemplo, cuando Graham, tras describir la geografia y el entorno citadino, cuestiona ciertos rumores peyorativos acerca del Almendral:

[...] si bien es el barrio más agradable de la ciudad, no lo consideran muy seguro para vivir en él sin peligro de ser robado y asesinado, por lo cual causó más asombro que aprobación mi propósito de alquilar una casa casi al fin del barrio. / Por mi parte, me siento muy tranquila, porque creo que nadie roba ó mata sin tentación y sin provocación; y como no tengo nada para tentar á los ladrones, no he de provocar tampoco á los asesinos (Graham, s/f, p. 157).

Las periodizaciones tradicionales coinciden en que es solo a partir de 1842, año en que José Victorino Lastarria redacta su famoso "Discurso Inaugural de la Sociedad Literaria", cuando comienza lo que, con propiedad, podría denominarse como literatura chilena. José Promis, sin embargo, puntualiza: "Aunque se puede aceptar que la literatura chilena no nació con Lastarria, como este quisiera que se pensara, tiene como acta de nacimiento su discurso" (Promis, 1977, p. 31). Es decir, se trata de una fecha convencional que, en cierto modo, simplifica un proceso más complejo en cuyo desarrollo -y esto es lo que nos interesa recalcar-fue crucial la participación de viajeros como María Graham y, según veremos a continuación, de intelectuales como Andrés Bello y Faustino Sarmiento, quienes, al decir de Juan Godoy, llegaron al país "impulsados por el espíritu romántico de la aventura, por la atracción que sentían hacia países lejanos, o por el ansia de liberarse de la opresión política que aquejaba a sus naciones de origen" (citado por Muñoz y Oelker, 1993, p. 20).

\section{LOS DEBATES FUNDACIONALES}

Pasando a un segundo hito, se deben señalar las controversias que animaron al denominado movimiento de 1842, de cuño romántico, y que se encuentran en la base de la literatura nacional. Entre estas sobresalen las discusiones intelectuales y políticas, que "se dirimieron públicamente en la prensa" (Jaksic, 2001, p. 163), entre Andrés Bello, exiliado de Venezuela en Inglaterra por exigencias de su labor diplomática y luego contratado por el gobierno chileno en 1829, Domingo Faustino Sarmiento, exiliado de Argentina por la dictadura de Juan Manuel de Rosas, y José Victorino Lastarria, rancagüino que en el seno del movimiento escribe la primera novela chilena, Don Guillermo (1842), ambientada en Valparaíso. Aquí nos interesa poner de relieve dos circunstancias: que las publicaciones que dieron tribuna a los debates fueron principalmente porteñas, como El Mercurio de Valparaíso, La Gaceta del Comercio y la Revista de Valparaíso (Muñoz y Oelker, 1993, p. 22), y que el desarrollo de esos debates y, por consiguiente, del movimiento de 1942, es impensable sin la participación de extranjeros exiliados que padecen en Chile su extrañamiento, como Bello y Sarmiento, entre otros ${ }^{3}$. Si bien no residían en Valparaíso, pensamos que el hecho de

\footnotetext{
${ }^{3}$ La Revista de Valparaíso fue fundada por Vicente Fidel López, y recibía las colaboraciones de Juan Bautista Alberdi (Hernández, 2001, p. 368). Al igual que Sarmiento, ambos exiliados por la dictadura de Rosas.
} 
que mantuvieran sus discusiones en la prensa porteña, discusiones que reterritorializan en Chile sus complejas experiencias políticas e intelectuales, necesariamente debió potenciar la formación de un campo literario en la ciudad. El crítico Norberto Pinilla llega a afirmar que el inicio del movimiento en realidad se remonta a 1841, cuando Sarmiento publica, precisamente en El Mercurio de Valparaíso, su comentario al poema de Andrés Bello "El incendio de la Compañía", pues "la cuestión de si 'Chile no es tierra de poetas", planteada por Sarmiento, instaló una discusión que "movilizó y consolidó a la naciente intelectualidad de la época" (Muñoz y Oelker, 1993, p. 20). En el marco de la controversia entre clasicismo y romanticismo, Sarmiento hirió el amor propio nacional sugiriendo una marcada tendencia a la réplica clasicista -reacia a la innovación romántica- en los literatos chilenos, y así propició las réplicas de figuras como Salvador Sanfuentes, José Joaquín Vallejo (Jotabeche) y su compatriota Vicente Fidel López (Jaksic, 2001, p. 176). Independiente de los pormenores del debate, la tesis de Pinilla situaría nada menos que en la ciudad puerto, gracias a la crítica de un argentino, y no en Santiago, gracias al discurso de un chileno -el joven Lastarria-, el nacimiento de la literatura chilena. Y es que, debido a su éxito material y a la iniciativa de inmigrantes, Valparaíso ya poseía, en ese entonces, un lugar sobresaliente en el ámbito de la letra impresa: aparte de las publicaciones mencionadas, agreguemos que contaba con la primera librería - fundada por el español Santos Tornero- y con la primera publicación diaria a nivel nacional (Hernández, 2001, p. 364). De hecho, Alfonso Larrahona, antologador de la poesía porteña, atribuye al auge económico el nacimiento de la literatura porteña y, en general, el nacimiento de la literatura de la quinta región. Además, agrega, la atmósfera burguesa y cosmopolita no solo impulsó en Valparaíso la actividad literaria e intelectual de poetas oriundos de la ciudad, sino también -como queda demostrado- de afuerinos atraídos por la celebridad que ella comienza a cobrar (Larrahona, 1999, p. 8). Sin embargo, a juicio de algunos comentaristas de la época, el reconocimiento social e institucional de la actividad literaria, en este contexto, es prácticamente nulo. A decir verdad, esta es toda una controversia durante la primera mitad del siglo XX, cuyos casos polares son la desazonada denuncia de un Valparaíso sin cabida para el arte y las letras, enarbolada por Joaquín Edwards Bello ${ }^{4}$ y la defensa de una sólida tradición porteña, encarnada por el periodista e historiador Roberto Hernández Cornejo ${ }^{5}$. Pero ambas posturas no se contradicen: la indiferencia institucional y el pragmatismo reinante no tendrían por qué haber suprimido la actividad literaria: de eso es prueba el propio Edwards Bello.

\footnotetext{
${ }^{4}$ En 1922, Joaquín Edwards Bello, anota: "Para Valparaíso la literatura es una tontería, una cosa de ingenuos, que hace perder a los hombres el carácter de seriedad burocrática y solvencia comercial que es lo más apreciado, casi lo único verdaderamente apreciado fuera del sport' (2008, p. 503).

${ }^{5}$ En 1921, Roberto Hernández afirma categóricamente: "No es exacta la aseveración tan frecuente de que Valparaíso, como emporio mercantil, como centro de las actividades del comercio, carezca de tradiciones de orden literario e intelectual que la señalen honrosamente ante el país entero" (2001, p. 364).
} 


\section{EL MODERNISMO Y LA POESÍA SOCIAL}

En este ambiente ostentoso y, al parecer, hostil para escritores e intelectuales, se enmarca la publicación en 1888 del libro que hace visible al modernismo latinoamericano, Azul ..., del nicaragüense Rubén Darío. Algunos de los cuentos más célebres del libro ("El rey burgués", "La canción del oro") a menudo alegorizan la dificultad de los poetas decimonónicos para ganar el reconocimiento y labrarse una posición socioeconómica acomodada en la pujante sociedad burguesa. Proveniente de un pueblito nicaragüense con rasgos sociales de comunidad colonial, donde el "poeta-niño" es reconocido y remunerado por su escritura -escribe epitafios y poemas para álbumes y abanicos (Concha, 1975, p. 27-28)-, en Valparaíso debe realizar actividades periodísticas e incluso trabajar en la aduana para sustentarse precariamente. Seducido y decepcionado por la sociedad burguesa, los parámetros coloniales de Darío deben reterritorializarse en Chile ${ }^{6}$. Esto se traspone a los poetas y artistas desplazados que pueblan su primer libro, cuyo sentimiento predominante es el resentimiento, como ha observado Grínor Rojo, y es que el traslado desde una Nicaragua provinciana a un Chile tan económicamente pujante como injusto y segregador, dice el crítico, le permite al poeta vislumbrar la entonces naciente modernización desigual de Latinoamérica, que deja a una parte importante de la población, incluido el artista, a la deriva de los beneficios modernizadores (2011, p. 162163). Un altivo desprecio, que encubre el deseo negado, alcanza niveles delirantes en la voz del poeta harapiento de "La canción del oro":

¡Eh, miserables, beodos, pobres de solemnidad, prostitutas, mendigos, vagos, rateros, bandidos, pordioseros, peregrinos, y vosotros los desterrados, y vosotros los holgazanes, y sobre todo, vosotros, oh poetas!

¡Unámonos a los felices, a los poderosos, a los banqueros, a los semidioses de la tierra!

¡Cantemos el oro! (Darío, 1978, p. 90).

Algo más de una década después de la partida de Darío, la ciudad de Valparaíso resulta pionera en la literatura social gracias a la obra poética y prosística de Carlos Pezoa Véliz, llegado desde Santiago ${ }^{7}$, y único poeta del período modernista que, a juicio de Ángel Rama, enfrenta abiertamente -sin la ambigüedad y el esteticismo de Darío-al "rey burgués", realizando una crítica directa a la injusta y segregadora modernización latinoamericana: “...el poeta rebelde, el profético y apocalíptico que se opone frontalmente al pensamiento y al arte de su tiempo, que anuncia una época de

\footnotetext{
${ }^{6}$ Las expectativas de Darío respecto de Chile, como un paraíso de cultura y riqueza, se aprecian en sus propias palabras: "Yo he oído de un ilustre amigo mío, Antonio Zambrana, pinturas de reuniones de literatos y poetas en la capital de Chile, no ha mucho tiempo, muy semejantes a un banquete de los antiguos filósofos, a un día del Agora [sic] o a una asamblea noble y erudita en el siglo XVII" (citado por Silva Castro, 1966, p. 21).

${ }^{7}$ Darío con seguridad se encuentra en Valparaíso entre 1886 y 1889. Carlos Pezoa Véliz, según la investigación de Raúl Silva Castro, habría llegado en 1900, pero el 31 de julio de 1902, cuando participa en una sesión del Ateneo de la Juventud de Valparaíso, sería la fecha datada de "incorporación de nuestro poeta en las filas de los poetas porteños" (2015, p. 76).
} 
transformación revolucionaria y como un San Juan predica la conversión"'(1985, p. 99). Al igual que Darío, Pezoa Véliz sufrirá el extrañamiento en una sociedad -la porteñadonde, debido al triunfo capitalista, todas las marginaciones se han extremado, incluida, por supuesto, la del poeta moderno: no solo la poesía no es retribuida materialmente, sino que la posición socioeconómica resulta ahí esencial para la aceptación social e incluso literaria. Por tanto, Pezoa Véliz se verá obligado a reterritorializar sus coordenadas santiaguinas en el campo cultural de Valparaíso. Así lo consigna Joaquín Edwards Bello en una semblanza en que rememora al poeta, cuya apariencia de "futre porteño"8 no lograba encubrir su origen humilde cuando se veía obligado a gastar sus últimos pesos en un "pequén", suerte de empanada de pino bastarda, como el supuesto origen del poeta (1973, p. 9). Por esta razón, parece fluctuar entre el enmascaramiento y una confrontacional autoaceptación: "El poeta Pezoa tuvo diversas figuraciones. Osciló, como diría Chocano, entre ser ácrata o aristócrata. Fue anarquista y siútico", y luego, significativamente añade el cronista: "En Valparaíso fracasó Rubén Darío en 1888. Pezoa, en 1908" (Edwards Bello, 1973, p. 9); se entiende que Darío por sus frustradas expectativas económicas tras la publicación de Azul..., y Pezoa Véliz por una enfermedad que lo lleva de vuelta a Santiago, donde muere. Pero más importante, es que al igual que Darío, Pezoa Véliz, en el extrañamiento de su situación porteña, acomoda, reterritorializa sus ínfulas y pretensiones: nunca deja de observar -pues comienza a reconocerlos como sus auténticos semejantes-a los menos beneficiados por esa riqueza y posición que, como el poeta nicaragüense, también Pezoa Véliz desea sin éxito. Por ejemplo, en poemas como "Nada" y "El pintor Pereza", que tematizan la exclusión del artista y su melancolía: en el primer poema, es ese poeta "siempre cabizbajo" que termina muerto a la intemperie e inidentificable, al parecer sin más papeles que los de su obra: "Entre sus papeles / no encontraron nada" (Pezoa Véliz, 1957, p. 77); y en el segundo, el pintor que padece "fatiga, neurosis, anemia moral", que "muere en silencio, de tedio, de esplín" y se niega a realizar su arte: "iQué ha de pintar si halla todo color gris!" (Pezoa Véliz, 1957, p. 73). En una crónica de 1906, uno de los paseantes de Pezoa Véliz se detiene a describir el ajetreo de la Plaza Echaurren, y ya solo tiene ojos para los hermanos del poeta moderno: “...acuden allí en busca de amparo los desocupados, los ebrios, los enfermos, los vagabundos, todos los náufragos de la vida" (2013, p. 63).

\section{LAS VANGUARDIAS EXPRESIONISTA E IMAGINISTA}

Ya en la tercera década del siglo XX irrumpen en Valparaíso las vanguardias, tanto en la poesía como en la narrativa. Adolfo de Nordenflycht observa que tras la lectura del manifiesto Non serviam (1914) de Vicente Huidobro en el Ateneo de

\footnotetext{
${ }^{8}$ Las dos acepciones registradas por la RAE se corresponden con la caricatura de Pezoa Véliz que acompaña la semblanza de Edwards Bello: "hombre joven que se compone mucho" y "Persona vestida con atildamiento" (en línea).
} 
Santiago, que inaugura la vanguardia en Latinoamérica, no se produce la consolidación de la nueva estética en el campo literario santiaguino, a causa de la predominancia del modernismo renovado de Gabriela Mistral, el joven Neruda y el grupo Los Diez, pero que "[e]n provincias la situación es distinta, y tal vez por el vacío de voces poéticas que se trasladaron a la capital, el terreno parecía más proclive para la experimentación de los jóvenes" ("La vanguardia", 2011, p. 120). Además, como se verá luego, la poesía porteña dispone de sus propias conexiones con Europa en el contexto de la modernización vanguardista de las literaturas hispanoamericanas. Gracias a los artistas que llegan directo desde Europa al puerto, se desarrollará ahí un imaginario artístico "más vinculado al expresionismo alemán que al creacionismo huidobriano de la capital" (Alberdi, 2013, p. 54).

$\mathrm{Al}$ respecto, es de suma importancia la figura del escritor húngaro Zsigmond Remenyik, vinculado al "activismo" literario -versión húngara del expresionismo alemán- quien, a partir de 1920, recorre Latinoamérica durante siete años. Posteriormente llega a Valparaíso y se incorpora al grupo de vanguardia liderado por Neftalí Agrella (1896-1957), del que forman parte otros extranjeros: Marko Smirnoff, propagandista ruso, y Jesús Carlos Toro, pintor mexicano (Alberdi, 2013, p. 52-53). En 1922 publican el manifiesto "Rosa Náutica" en la revista mural Antena, hoja vanguardista $\mathrm{N}^{\circ} 1$, firmada por un numeroso contingente de jóvenes porteños, al que adhirieren figuras sobresalientes de la vanguardia hispanoamericana como Vicente Huidobro, Jorge Luis Borges, Manuel Maples Arce y Guillermo de Torre. Un ejemplo significativo del proceso de desterritorialización de Remenyik es su extrañamiento de la lengua que ha quedado registrado tanto en sus textos dramáticos como programáticos escritos en Valparaíso durante 1922 (luego publicados en Lima en 1923). Por ejemplo, el manifiesto Cartel Núm. III, cuyas anomalías sintácticas lo dotan de una particular expresividad e irreverencia acordes con los ánimos vanguardistas, a la vez que tensionan la cultura y lengua europeas en el ámbito porteño: "Mis palabras primitivas en esta tierra donde no podía hablar yo bien, únicamente del amor y del dolor y de la miseria en que a veces me encontré, se pierden como me voy a perder una vez yo también!" (Remenyik, 2016, p. 2). En Valparaíso, el europeo extraña su lengua y aprende precariamente el español, modulando una lengua "primitiva", una especie de registro propio que busca expresar su proceso de desterritorialización lingüística, subjetiva y territorial, objetivado en la miseria que dice haber padecido.

En cuanto a la vanguardia narrativa, surgida en la misma década, se debe mencionar el imaginismo, caracterizado por las atmósferas de fantasía y misterio, de emotividad y nostalgia, en un afán de romper con la noción reducida de realidad del realismo francés y el criollismo nacional (Muñoz y Oelker, 1993, p. 127-128). Sus obras más conocidas y representativas se inspiran en la vida marítima de Valparaíso. Estas son, a nuestro parecer, Valparaíso, puerto de nostalgia (1955, versión aumentada y corregida de Piel nocturna 1936), y Mónica Sanders (1951) de Salvador Reyes. 
Muñoz y Oelker explican la irrupción del imaginismo ${ }^{9}$ como un producto de los afanes cosmopolitas de las clases medias afianzadas en el poder, que poco antes apelaban a lo autóctono en contra de la aristocracia europeizante; también lo consideran como una respuesta de la misma clase al quiebre institucional de los años veinte (1993, p. 130). Por su parte, Nordenflycht piensa que:

[...] la narrativa imaginista le proporciona un discurso al imaginario colectivo del Valparaíso de los años 1930 que iba abandonando el mito prometeico de progreso y modernización que acompañó al desarrollo del Puerto desde mediados del siglo XIX, pero que los duros acontecimientos económicos se encargaban de menguar ("Valparaíso como espacio", 2011, p. 70).

$\mathrm{Al}$ imaginismo se debe, entonces, la invención de la bohemia porteña, que idealiza el pasado cosmopolita, la historia de transculturación y desterritorialización propia de Valparaíso. No es irrelevante que la articulación de este nuevo imaginario la realice un nortino, cuya ciudad de origen, Copiapó, tanto como Antofagasta, Taltal, y Caldera, que habitó posteriormente, se diferencian radicalmente de Valparaíso en el clima y el paisaje. Salvador Reyes, con el extrañamiento propio de la mirada extranjera, elabora en sus novelas una imagen de la ciudad -donde campean los bares, cabarets y prostíbulos-que hasta el momento se había evaluado despectivamente en el contexto de la decadencia económica. Solo a la mirada del afuerino Valparaíso puede aparecer "como un laberinto en el cual era fácil perderse para siempre de la rutina” (Reyes, 1955, p. 35), según comenta el narrador de Valparaíso, puerto de nostalgia. Solo para el afuerino es admirable, según se aprecia en el enfoque narrativo, il dolce far ni ente al que se entregan los personajes de la misma novela: " . . . a veces jugaban a las cartas, a veces charlaban o, simplemente, se metía cada uno en su rincón y permanecían fumando en silencio" (Reyes, 1955, p. 41).

\section{LA NOVELA SOCIAL}

El quinto hito corresponde a unas circunstancias históricas, la década de los cincuenta, en que ya resulta insoslayable la emergencia de las clases obreras en Chile y algunos novelistas afuerinos incorporan el territorio del cerro y sus comunidades. Es lo que hace Manuel Rojas en Hijo de ladrón (1951), donde además, dice el autor, ficcionaliza su propia experiencia en la ciudad, tras cruzar la cordillera desde Argentina, su país natal:

El motín que se describe ocurrió en Valparaíso, en 1914 o principios de 1915, no recuerdo exactamente, y lo que ahí le sucede a Aniceto Hevia es exactamente lo que me ocurrió a mí, con la diferencia de que yo no enfermé; después de doce días de detención fui puesto en libertad (citado por Rojo, 2014, p. 212).

\footnotetext{
${ }^{9}$ Los autores puntualizan que ni “estos 'grandes imaginistas' ni tampoco los 'imaginistas puros' de que habla Manuel Vega tienen relación con los 'imaginistas' ('imagists'), grupo de poetas ingleses y norteamericanos (Ezra Pound, Hilda Doolittle, Richard Aldington, D.H. Lawrence) que hacia 1914 formaron el movimiento literario denominado ‘imaginismo' ('imagism')” (Muñoz y Oelker, 1993, p. 76).
} 
Como Rojas, Aniceto se encuentra con estas agitadas circunstancias sociales en la ciudad puerto. Cesante y desamparado, desterritorializado, se detiene a observar a los manifestantes del motín, momento en que su mirada y la novela mapean e incorporan los cerros, las quebradas y el entorno portuario, así como a sus relegados habitantes y trabajadores:

[...] habían bajado quién sabe desde qué cerro y por qué callejones o quebradas. Lecheros o Calaguala, Las Violetas o La Cárcel, El Barón o La Cabritería o quizá surgido de los talleres, del dique de los barcos, de las chatas; algunos llevaban aún su saquillo con carbón o leña y se veía a varios con los pantalones a media pierna, mostrando blancos calzoncillos; otros iban descalzos [...] (Rojas, 1961, p. 461).

La mirada de Aniceto no rehúye a los ladrones oportunistas que se cuelan en la protesta y carecen de toda ética. Son los "hombres-ratas" que viven en el cauce de la avenida Argentina: "Generaciones enteras de vagos habían surgido de aquel cauce; de las pocilgas en que nacían, pasaban al cauce, del cauce a las aceras a pedir limosna o a robar" (Rojas, 1961, p. 470). Aparecen entonces las clases populares y marginales que hasta el momento no participan de los anteriores imaginarios porteños, al menos de los más legitimados. Hacia el final de la novela, Aniceto conoce a Alfonso Echeverría, alias El Filósofo, y a Cristián Ardiles en la caleta El Membrillo, con quienes comienza a vivir en el cuarto de un conventillo, en un cerro indeterminado, y a trabajar junto con ellos como "maestro chasquilla". Los tres forman, entonces, una comunidad opuesta en todo a los valores que priman en el plan, y es que, según Grínor Rojo, "[1]os valores del sistema burgués no son los de esta comunidad [...] Ni el trabajo, ni el dinero, ni la casa, ni la familia [...] ni la previsión del porvenir son consideraciones de importancia" (2014, p. 227).

Siguiendo un trayecto similar y complementario a la novela de Manuel Rojas, la novela El mundo herido (1955), del santiaguino Armando Méndez Carrasco, se introduce aún más en el mundo de la pobreza de los cerros y los "hombres-ratas". Como la novela de Rojas, también presenta rasgos autobiográficos -Méndez Carrasco nació en Santiago, pero pasó parte de su infancia en los cerros de Valparaíso-e igualmente se estructura según el género formativo subrayando unos valores opuestos a la sociedad burguesa. El protagonista y narrador de la novela es el Curipipe, niño de familia disfuncional del cerro El Litre, para quien el plan es sinónimo "de ahogo, de casas raídas, de calles plagadas de gente, de carruajes, de animales embrutecidos por el sudor, de desorden civilizado" (Méndez Carrasco, 1955, p. 134). En cambio, la quebrada y los cerros se le aparecen como lugares muy distintos: "Algo de ese fértil lugar [la quebrada El Vergel] me hacía olvidar la ciudad y la tristeza del hambre" (Méndez Carrasco, 1955, p. 12); "El cerro me ofreció una concepción infinita del porqué de mis pasos terrenales" (Méndez Carrasco, 1955, p. 134). Además, si en la novela la institucionalidad del plan -la familia, la iglesia, el reformatorio- se define por su hipocresía e inoperancia, la comunidad espontánea de los 
niños del cerro se define por una cierta integridad moral. Hambriento y con la cabeza poblada de piojos, el Curipipe solo encuentra acogida fuera de su hogar:

Me dirigía a la calle, y buscaba la amistad de los niños más pobres, porque solo a ellos admiraba. Algunos no tenían dónde dormir, y sin embargo genuinas risotadas surcaban sus rostros. Yo conocía la extraordinaria solidez de sus espíritus por la risa espontánea y la idea de esperanza que jamás les abandonaba (Méndez Carrasco, 1955, p. 12).

Como la de Aniceto, la comunidad de los "niños-rata" que admira el Curipipe -y a la que, por su condición comparativamente más acomodada, pertenece solo como simpatizante-, tampoco gira en torno al trabajo, el dinero, la casa, o la previsión del porvenir, aunque resulta bastante más afiatada por lazos afectivos. Pero en ambos casos, trasponiendo la experiencia de sus autores, los protagonistas logran ver mejor lo que ven porque lo hacen con la mirada del extrañamiento -Aniceto, "exiliado" de su patria por la disolución familiar; el Curipipe "exiliado" de su hogar por la negligencia de los padres-, que les permite reterritorializarse en sus respectivas comunidades porteñas alternativas.

\section{LA NOVELA DEL APROVINCIAMIENTO}

En la década de los sesenta, al consolidarse el proceso de aprovinciamiento de Valparaíso $^{10}$, las novelas más sobresalientes se orientan menos hacia una comunidad utópica que a unos individuos desencantados en búsqueda solitaria de algún sentido. En Sueldo vital (1964), de Carlos León, originario de Coquimbo, el narrador personaje, Carlos -también llegado de otra ciudad, aunque recientemente cuando comienza la novela-, obtiene en Valparaíso un empleo de copista, monótono y alienante. Pero sus tiempos libres no son mucho mejores: ni en la bohemia, ni en la actividad gremial, ni en el sexo o las relaciones sentimentales encuentra sentido a su existencia; al contrario, le parecen instancias orientadas por el interés más egoísta. La escapatoria definitiva se anuncia cuando Carlos asiste a un concierto gratuito de ópera. Ahí, pese a su reticencia inicial, la emoción espontánea, sin pretensiones, de los asistentes, propicia por fin una comunidad no fundada en el interés personal: “...en los conciertos tradicionales la armonía era meramente musical, mientras que en el presente existía un acuerdo, un concierto no solo de temas y de notas, sino también de seres humanos" (León, 1989, p. 213). Por fin Carlos accede, por medio del arte, a una comunicación plena. Esta epifanía

\footnotetext{
${ }^{10}$ Nordenflycht utiliza el término de "aprovinciamiento" para referirse al largo proceso de decadencia y aislamiento sufrido por Valparaíso luego de su auge económico en la segunda mitad del siglo XIX: “....al cabo de unas décadas, y ya entrado el siglo XX, Valparaíso, a raíz de circunstancias como el terremoto de 1906, la apertura del Canal de Panamá, el crecimiento del cercano puerto de San Antonio, el declive de las exportaciones de nitrato causada por la invención del salitre sintético en Alemania, el desplazamiento de las elites comerciales y la concentración de capitales en Santiago, pierde su impulso y empieza a evidenciar síntomas de 'aprovinciamiento"' (2010, p. 163).
} 
profana lo libera fugazmente de la pesadilla de su historia sin embrutecerlo: "Me siento, de pronto, libre, sin pasado ni futuro, absorbido por el encanto absoluto de la calle y el agrado de caminar" (León, 1989, p. 213). El sentido de su existencia, descubre hacia el final de la novela, se encuentra en el arte literario, que expresa y recobra la individualidad expropiada por la sociedad y el trabajo. En la soledad de su cuarto, Carlos se entrega, entonces, a la escritura: ahí, "como motivo central aparece el yo dispersado, que aspira a reintegrarse, para salvar de la ruina, la desolación y el caos su propia unidad. La luz artificial inicia su derrota. Empieza a clarear" (León, 1989, p. 241). Mediante el arco formado por la escena musical y el descubrimiento literario, Sueldo vital plantea que solo mediante el arte sería posible la liberación del individuo y la conquista de una existencia más auténtica, opuesta a la sociedad artificial integrada por seres mecanizados y homogéneos.

La novela Sabadomingo (1973) de Juan Uribe Echevarría, inmigrante español nacido en Bilbao, no es mucho más optimista respecto de la sociedad porteña de ese momento y también incluye elementos autobiográficos. Según anota Enrique Lafourcade: "Juan Uribe, como [Manuel] Rojas, se da entero en el libro. Es él mismo el héroe. 'Un profesor que mira el mundo"' (2001, p. 467). Siguiendo los pasos de este profesor, Pedro Maturana, el narrador hará visible el mapa social de Viña del Mar y Valparaíso: la panorámica del ajetreo deportivo viñamarino en el Sporting Club y las canchas de tenis de Chorrillos, donde se reúne la elite criolla e inmigrante, contrasta con el sector de las apuestas hípicas donde, "como escenas de un país diferente" (Uribe Echevarría, 1973, p. 7), se encuentra el protagonista con una multitud de personajes de clase popular. En Valparaíso Maturana "[v]agó por la calles del centro hasta la hora de comer, por las calles elegantes que siempre había evitado: Condell, Esmeralda, acribilladas de avisos luminosos. Eran las calles de los otros" (Uribe Echevaría, 1987, p. 36). Anota Lafourcade un "desfile de pícaros, bohemios anarquistas, daifas, mafiosos y apostadores" que, sin embargo, no aparecen nítidamente perfilados (2001, p. 467). La aglomeración de personajes, añade Lafourcade, causa una sensación de inmovilidad, a lo que se suma un tiempo histórico borroso y un espacio porteño que se vislumbra solo desde el interior de sus bares (2001, p. 468). La representación grupal, pensamos, es coherente con la poética popular, comunitaria, de la novela; pero conjugada con el afecto nostálgico y la ausencia de espacios abiertos, evidencia una ansiosa desazón por acumular y catalogar los elementos de un pasado lleno de sentido para apuntalar con ellos un presente desolador. Significativamente, hacia el final de la novela y del fin de semana de juerga, el protagonista experimenta cierta iluminación en medio de ese espacio asfixiante: "Como despidiéndose, observó con cariño los rostros borrosos y fatigados de sus amigos. Extraño y agradable estupor nubló sus ojos. Una franja de luz débil, azulosa, se filtraba, bajo la cortina metálica, a ras del suelo..." (Uribe Echevarría, 1973, p. 190). Pero esta vez no es la epifanía del arte como en Sueldo vital, sino simplemente la iluminación del amanecer que despierta a la novela de su nostalgia por una sociedad porteña más solidaria -la de 
fines de los años treinta- inexistente al comienzo de los setenta (Nordenflycht, 2009, p. 159).

Los protagonistas de ambas novelas -transposiciones de un afuerino norteño y un inmigrante español-, extrañados ante una ciudad monótona e inmóvil, buscan desesperadamente dotar de sentido al territorio, limitado al plan en la representación espacial $^{11}$. Y lo hacen con significantes culturales de prestigio europeo en un Valparaíso para entonces carente de esplendor cosmopolita: Carlos por medio de la epifanía del arte, bajo una concepción "belleletrística" y redentora de la escritura; el profesor Maturana mediante una bohemia donde la cultura popular aparece filtrada por un distanciamiento académico, antropológico: "también me gustan el vino y la gente del pueblo" (Uribe Echevarría, 1973, p. 21), le dice el poeta Galdames al profesor. En esto coinciden autor implícito y real: “...suele prevalecer en él [Juan Uribe Echevarría] el profesor y el investigador folklórico" (Lafourcade, 2001, p. 468). En ambas novelas, es paradójico, la reterritorialización de Valparaíso y su gente sucede a espaldas del territorio y la comunidad.

\section{LOS POETAS EXILIADOS}

En las décadas del sesenta y setenta del siglo XX aparecen las voces poéticas de Alicia Galaz, Eduardo Embry, Luis Mizón y Osvaldo “Gitano" Rodríguez, autores que conformarán la diáspora chilena del exilio y escribirán parte de su obra en el extranjero. Aquí la mecánica de desterritorialización/reterritorialización ya no es la de los afuerinos y extranjeros que llegan a escribir acerca de sus experiencias en la ciudad, sino la de los porteños que abandonan Valparaíso para evocarlo y recrearlo en la distancia. En Galaz, Rodríguez, Mizón y Embry prevalecerá el extrañamiento del Valparaíso previo al golpe de Estado y la dictadura militar que los lleva al exilio, contexto en el que participaron activamente por sus intereses culturales y políticos. Osvaldo Rodríguez actúa en la película Ya no basta con rezar (1972), de Aldo Francia -en que se aprecia claramente el ambiente utópico y reivindicativo porteño-, apoyando una huelga obrera durante el gobierno de Eduardo Frei Montalva, en 1967. Además, lo hace apropiándose de su propia figura artística -el "Gitano"- vinculada al movimiento de La nueva canción chilena, de tendencia izquierdista. Luis Mizón se afilia al Partido Comunista, realiza un programa en la radio "Caupolicán", dirige la revista de la Escuela de Derecho de la PUCV y es vicepresidente de la organización de su barrio para el aprovisionamiento de comestibles. Eduardo Embry también participa en programas radiales e incluso

\footnotetext{
${ }^{11}$ Lo que Nordenflycht dice de Juan Uribe Echevarría en Sabadomingo y de Alfredo González en De carne y sueño (1995), se hace extensivo a Carlos León en Sueldo vital: "El Valparaíso de que hablan estos autores es el del 'plan', del que los referentes mar y cerro, con que normalmente se sitúa el transeúnte, quedan silenciados, casi desaparecidos [...] González y Uribe escriben sobre un Valparaíso que ha dado la espalda al mar, y al paisaje natural del entorno [...] Es una escritura que, alejada del puerto y su actividad mercantil, naviera y cosmopolita, parece 'aprovinciarse' en el Almendral y sus personajes acuartelarse en los bares, tabernas y pensiones” (2009, p. 158).
} 
televisivos de Valparaíso que intentan hacer visible y legitimar el movimiento social. Alicia Galaz se desempeña como profesora de literatura en la sede de Tarapacá de la Universidad de Chile y como directora de la revista Tebaida que reúne a varios escritores e intelectuales de izquierda. $\mathrm{Y}$ aunque se encuentra en otro entorno provinciano al momento de su exilio, su infancia y adolescencia transcurren en Valparaíso, al que añora insistentemente en la distancia, como se aprecia en el siguiente poema de Señas distantes de lo preferido (1990):

Los momentos de la memoria son míos y los repaso:

las manos de mi padre mojadas de mis lágrimas

un día de invierno y mi madre que lava la herida

con el perfume de Valparaíso marino y natal [...] (Galaz, 1990, p. 13).

El recuerdo se atesora y sirve de consuelo ante la herida del exilio, por esta razón estos poetas incorporan a sus obras el espacio de la ciudad y los afectos con que este se reconstituye en su historia personal desde la perspectiva del presente, confrontando y condensando los imaginarios propios con los que se les ofrecen en los nuevos territorios de acogida. Esto es recurrente sobre todo en la poética de Osvaldo Rodríguez y, en particular, en los poemas de Canto de extramuros (1994):

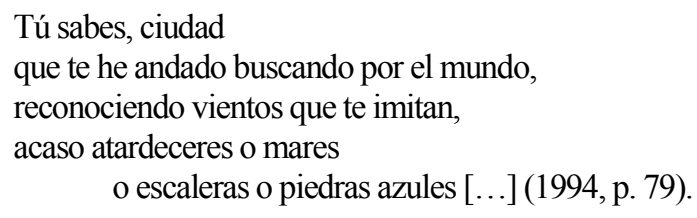

La reterritorialización de Valparaíso mediante la elaboración poética en medio del extrañamiento del exilio, a menudo aparecerá en esta poesía como un ejercicio vano e infructuoso, lo que se pone de relieve en algunos fragmentos del extenso poema "El árbol", de Luis Mizón, incluido en Poema del sur (1982):

Emigrantes
casi no tenemos recuerdos
solo una herencia vaga de objetos
que no sirven a nadie [...] (1982, p. 48 , cursiva en el original).

Y es que la fluctuación entre consuelo y desazón es propia del extrañamiento como lúcidamente señala el propio Luis Mizón reflexionando acerca de su condición de exiliado en una conferencia que por su valor documental y crítico citamos en extenso:

La palabra "extrañar" significa deportar, exiliar, echar del país, alejar, rechazar, relegar, pero también el efecto que ese alejamiento produce, el echar de menos. Ese alejamiento sin embargo no es completamente negativo y lleva a veces a la persona relegada o extrañada a conocer cosas curiosas y sorprendentes, países y costumbres nunca vistas que forman parte de su riqueza y de su experiencia cultural [...] Por su parte la palabra "entrañable" define algo íntimo o afectuoso, verdadero o sincero. 
"Entrañar" es contener en germen, guardar una cosa y llevarla consigo en lo más profundo del ser (2011, párr. 2) ${ }^{12}$.

Reflexiones extensibles al resto de los poetas porteños del exilio que incorporan esta experiencia a su poesía: con distintos énfasis, el extrañamiento aparece ahí en tanto pena o condena, y como ese "echar de menos" que vuelve más "entrañables" los recuerdos y la relación con el pasado traumático. En Eduardo Embry, por ejemplo, el exilio es ya una condición intrínseca al ser humano, de la que, por tanto, no es pertinente lamentarse: "Foráneo en estos lados, y foráneo / hasta en la luna, eso es lo que somos" (2010, p. 64).

Tanto para estos poetas porteños exiliados en otros países como para el resto de los escritores extranjeros o afuerinos que por distintas circunstancias llegaron a Valparaíso y escribieron respecto de la ciudad, la escritura se convierte en herramienta de orientación y territorio; territorio fisurado, pero también lugar de acogida, marcado por la doble huella del extrañamiento (entre lo extraño y lo entrañable) y el proceso de desterritorialización/reterritorialización; territorio en el que habitan sus identidades igualmente fisuradas pero donde, al mismo tiempo, se les ofrece la posibilidad de reconfigurarlas y enriquecerlas con las pérdidas y ganancias de su habitar fluctuante entre el pasado y el presente, entre el allá y el aquí.

\title{
Universidad Academia de Humanismo Cristiano* \\ Facultad de Pedagogía Agustinas 2071, Santiago (Chile) xfigueroa@academia.cl
}

\author{
Pontificia Universidad Católica de Valparaíso** \\ Instituto de Literatura y Ciencias del Lenguaje \\ Av. El bosque 1290, Viña del mar (Chile) \\ fgonzalez.alfonso@gmail.com
}

\section{OBRAS CITADAS}

Alberdi Soto, Begoña (2012). "La otra vanguardia: El expresionismo de Valparaíso en su Revista Litoral". Mapocho. Revista de Humanidades 71: 51-71.

Bravo Acevedo, Guillermo (1987). "La crisis de 1929 y los problemas de la sociedad urbana de Valparaíso". Valparaíso 1536-1986. Primera Jornada de Historia Urbana. Valparaíso: Altazor.

Concha, Jaime (1975). Rubén Darío. Madrid: Júcar.

Chandía, Marco (2013). La cuadra. Pasión, vino y se fue... Cultura popular y memoria histórica en el Barrio Puerto de Valparaíso. Santiago: RIL.

\footnotetext{
${ }^{12}$ Esta conferencia fue leída por Luis Mizón en el Departamento de Literatura Comparada de la Universidad Sorbonne-Nouvelle el año 2011, y nos fue cedida por el autor vía correo electrónico el 16/03/2016.
} 
Darío, Rubén (1978). Azul y poemas. Santiago: Editorial Andrés Bello.

De Nordenflycht, Adolfo (2011a). "La vanguardia de Valparaíso: expresionismo de/en la periferia". Estudios filológicos 47 (junio): 115-131.

_ (2011b). "Valparaíso como espacio de la aventura en el imaginario de la narrativa imaginista". Atenea 504: 55-72.

_ (2010). “'Los jaguares se van': provincia e imaginario local de Valparaíso en Sueldo vital de Carlos León". Anales de literatura chilena 14 (diciembre): 157-172.

(2009). "El imaginario de Valparaíso a mediados del siglo XX en Sabadomingo, novela de Juan Uribe, y en De carne y sueño, memorias de Alfredo González". Aisthesis 45: 154-166.

Edwards Bello, Joaquín (2008). "IX Valparaíso". Crónicas reunidas (I). Santiago: Ediciones Universidad Diego Portales.

— (2001). "Cómo era entonces Valparaíso y cómo vivía su gente". Memorial de Valparaíso. Calderón, Alfonso y Marilis Schlotfeldt (comp.). Santiago: RIL.

_ (1973). "Notas sobre Pezoa Véliz". 01 Jul. 1973. La Nación. Disponible en: http://www.memoriachilena.cl/602/w3-article-121383.html

Embry, Eduardo (2010). Al revés de las cosas que en este mundo fenecen. Valparaíso:

Ed. Facultad de Humanidades de la Universidad de Playa Ancha.

Estrada Turra, Baldomero (2013). "Importancia económica de los alemanes en Valparaíso, 1850-1915". América Latina en la Historia Económica 20 (mayo-agosto): 151-176.

Galaz, Alicia (1990). Señas distantes de lo preferido. Concepción: Lar.

Graham, María (s/f). Diario de mi residencia en Chile. Madrid: Editorial América.

Hernández, Roberto (2001). "Apuntes históricos sobre el movimiento literario general de Valparaíso". Memorial de Valparaíso. Calderón, Alfonso y Marilis Schlotfeldt (comp.). Santiago: RIL.

Herner, María Teresa (2009). "Territorio, desterritorialización y reterritorialización: un abordaje teórico desde la perspectiva de Deleuze y Guattari". Huellas 13: 158-171.

Jaksic, Iván (2001). Andrés Bello: la pasión por el orden. Santiago: Editorial Universitaria.

Lafourcade, Enrique (2001). "Valparaíso, nostalgias sin puerto". Memorial de Valparaíso. Calderón, Alfonso y Marilis Schlotfeldt (comp.). Santiago: RIL Editores.

Larrahona, Alfonso (1999). Historia de la poesía en Valparaíso. Siglos XIX y XX. Valparaíso: Ediciones Correo de la Poesía.

León, Carlos (1989). Sueldo vital. Santiago: Editorial Andrés Bello.

Lins Ribeiro, Gustavo (1989). "Descotidianizar. Extrañamiento y conciencia práctica, un ensayo sobre la perspectiva antropológica". Cuadernos de Antropología Social Vol. 2, № 1: 65-69.

Méndez Carrasco, Armando (1955). El mundo herido. Santiago: Editorial Cultura. Mizón, Luis (2011). "Una experiencia literaria del exilio". Departamento de Literatura Comparada de la Universidad Sorbonne-Nouvelle, Conferencia inédita. 
__ (1982). Poème du Sud et autres poèmes (Edición bilingüe. Trad. Roger Caillois y Claude Couffon). París: Gallimard.

Muñoz, Luis y Dieter Oelker (1993). Diccionario de movimientos y grupos literarios chilenos. Concepción: Ediciones Universidad de Concepción.

Ortega, Luis (1987). "Valparaíso: comercio exterior y crecimiento urbano entre 1800 y 1880". Valparaíso 1536-1986. Primera Jornada de Historia Urbana. Valparaíso: Ediciones Altazor.

Pezoa Véliz, Carlos (2013). "Vistas de Valparaíso: La plaza de la miseria". Serie prosas de Carlos Pezoa Véliz. Cuadernillo 3 de 6: Discursos y prácticas de la precariedad. Valparaíso: Ediciones Perro de Puerto.

— (1957). Antología. Selección prólogo y notas de Nicomedes Guzmán. Santiago: Zig-Zag.

Promis, José (1977). "Las ideologías generacionales de la literatura chilena a través de documentos literarios". Testimonios y documentos de la literatura chilena (1842-1975). Santiago: Editorial Nascimento.

Rama, Ángel (1985). Rubén Darío y el modernismo. Barcelona: Alfadil Ediciones.

Remenyik, Zsigmong (2016). "Cartel $\mathrm{N}^{\circ}$ III". Las tres tragedias del lamparero alucinado. Valparaíso: Ediciones del Caxicondor.

Reyes, Miriam (2011). "La desterritorialización como forma de abordar el concepto de frontera y la identidad en la migración". Revista Geográfica de América Central. Número Especial EGAL (segundo semestre): 1-13.

Reyes, Salvador (1955). Valparaíso, puerto de nostalgias. Santiago: Zig-Zag.

Rodríguez, Osvaldo (1994). Cantos de extramuros. Valparaíso: Umbral.

Rojas, Manuel (1961). "Hijo de ladrón". Obras completas de Manuel Rojas. Santiago: Zig-Zag.

Rojo, Grínor (2014). "La contrabildungsroman de Manuel Rojas". Las novelas de formación chilenas. Bildungsroman y contrabilgdunsroman. Santiago: Sangría.

__ (2011). "1888: Darío, Azul... y el modernismo". Clásicos latinoamericanos. Para una relectura del canon. Volumen I. El siglo XIX. Santiago: LOM.

Sánchez, Alfredo y Cecilia Jiménez (2011). "Valparaíso: la ciudad-puerto más importante de Chile y la vulnerabilidad de su patrimonio arquitectónico a los riesgos sísmicos". Estudios Geográficos 271 (julio-diciembre): 559-589.

Silva Castro, Raúl (2015). Carlos Pezoa Véliz (1879-1908). Santiago: Ediciones Tácitas.

— (1966). Rubén Dario a los veinte años. Santiago: Andrés Bello.

Uribe Echevarría, Juan (1973). Sabadomingo. Santiago: Editora Nacional Gabriela Mistral. 